\title{
Localized Wave Pulses in the Keyport Experiment
}

\author{
David H. Chambers \\ D. Kent Lewis
}

This paper was prepared for submittal to the 16th International Congress on Acoustics and 135th Meeting Acoustical Society of America

Seattle, Washington

June 20-26, 1998

February 17, 1998

This is a preprint of a paper intended for publication in a journal or proceedings. Since changes may be made before publication, this preprint is made available with the understanding that it will not be cited or reproduced without the permission of the author. 


\section{DISCLAIMER}

This document was prepared as an account of work sponsored by an agency of the United States Government. Neither the United States Government nor the University of California nor any of their employees, makes any warranty, express or implied, or assumes any legal liability or responsibility for the accuracy, completeness, or usefulness of any information, apparatus, product, or process

disclosed, or represents that its use would not infringe privately owned rights. Reference herein to any specific commercial product, process, or service by trade name, trademark, manufacturer, or otherwise, does not necessarily constitute or imply its endorsement, recommendation, or favoring by the United States Government or the University of California. The views and opinions of authors expressed herein do not necessarily state or reflect those of the United States Government or the University of California, and shall not be used for advertising or product endorsement purposes. 


\title{
Localized Wave Pulses in the Keyport Experiment
}

\author{
David H. Chambers and D. Kent Lewis \\ Lawrence Livermore National Laboratory, P.O. Box 808, MS L-372, Livermore, CA 94551
}

\begin{abstract}
Localized wave (LW) pulses were produced using a standard Navy array in the anechoic tank at NUWC Keyport. The LW pulses used were the MPS pulse first derived by Ziolkowski, and a new type of pulse based on a superposition of Gaussian beam modes. This new type is motivated by a desire to make a comparison of the MPS pulse with another broad band pulse built from solutions to the wave equation. The superposed Gaussian pulse can be described by parameters which are analogous to those describing the MPS pulse. We compare the directivity patterns and the axial energy decay between the pulses. We find the behavior of the pulses to be similar so that the superposed Gaussian could be another candidate in the class of low diffractive pulses known as localized waves.
\end{abstract}

\section{INTRODUCTION}

Several kinds of low diffraction pulses have been formulated in the last several years. Among these are Greenleaf and Lu's X waves [1], Brittingham's Focused Wave Modes (FWM) [2], Ziolkowski's Modified Power Spectrum (MPS) pulse [3,4], and Stepanishen and Sun's transient Bessel beams [5]. All of these are formulated as direct pulse solutions of the scalar wave equation or superpositions of direct solutions. In this paper we compare the directivity patterns and down range energy decay rates of the MPS pulse and a new broad band pulse formulated as a superposition of single frequency Gaussian beams. The measurements were performed in an anechoic tank at NUWC Keyport. The pulses were produced by a standard acoustic array (AdCap) used by the U. S. Navy. Details of the experiment are reported in the accompanying paper by Lewis and Chambers [6].

\section{FORMULATION OF SUPERPOSED GAUSSIAN PULSE}

The original intent of the Keyport experiment was to produce an MPS pulse using the AdCap array. However, a second type of broad band pulse was desired for comparison. Since the MPS pulse was originally formulated as a superposition of Focused Wave Modes, we designed this second pulse as a superposition of Gaussian beam modes. We chose Gaussian beam modes because of their widespread use to describe forward propagating beams even though they are not exact solutions of the wave equation. The fundamental mode Gaussian beam is given by [7]

$$
u_{k}(r, z, t)=\frac{k w_{0}^{2} \exp (i(\omega t-k z))}{k w_{0}^{2}-2 i\left(z-z_{0}\right)} \exp \left(-\frac{k r^{2}}{k w_{0}^{2}-2 i\left(z-z_{0}\right)}\right),
$$

where $\mathrm{k}=\omega / \mathrm{C}$ is the wave number, $\omega$ the angular frequency, $\mathrm{w}_{0}$ the beam waist, and $\mathrm{z}_{0}$ is the focal distance from the aperture. A superposition of Gaussian beams of different frequencies can be written as

$$
\Phi(r, z, t)=\int_{0}^{\infty} \hat{\Phi}(\omega) \frac{\left.\omega w_{0}^{2} \exp i \omega(t-z / c)\right)}{\omega w_{0}^{2}-2 i c\left(z-z_{0}\right)} \exp \left(-\frac{\omega r^{2}}{\omega w_{0}^{2}-2 i c\left(z-z_{0}\right)}\right) d \omega
$$

where $\hat{\Phi}(\omega)$ is the weighting for the beam with angular frequency $\omega$. In order to obtain a simple analytical form the beam waist is chosen to be a function of frequency, $w_{0}(\omega)=r_{0} \sqrt{\omega_{0} / \omega}$, and the weighting is chosen to be $\hat{\Phi}(\omega)=\exp \left(\omega / \omega_{0}\right) / \omega_{0}$. With these choices the integral can be performed giving the final expression for the acoustic potential of the SG pulse: 


$$
\Phi(r, z, t)=\operatorname{Re}\left[\frac{1}{r^{2} / r_{0}^{2}+\left(1-i \omega_{0}(t-z / c)\right)\left(1-2 i c\left(z-z_{0}\right) / \omega_{0} r_{0}^{2}\right)}\right]
$$

The parameters $r_{0}$ (pulse radius), $z_{0}$, and $\omega_{0} \neq 2 \pi f_{0}$ ), completely specify the SG pulse.

In comparison, the acoustic potential for the MPS pulse is given by

$$
\Phi(r, z, t)=\operatorname{Re}\left[\frac{2 R_{m} z_{0}}{z_{0}+i(z-c t)} \frac{\exp \left(z_{0} s(z, r, t) / w_{0}^{2}\right)}{s(r, z, t)+2 R_{m}}\right] \quad s,(r, z, t)=\frac{r^{2}}{z_{0}+i(z-c t)}-i(z+c t)
$$

where $w_{0}$ is the pulse radius, $z_{0}$ is the pulse axial halfwidth, and $R_{m}$ is the range scale length. These parameters are related to Ziolkowski's MPS parameters a, b, and $\beta$ (ref. 3) by

$$
\mathrm{a}=\frac{1}{\mathrm{z}_{0}} \quad, \mathrm{~b}=\frac{2 \mathrm{R}_{\mathrm{m}} \mathrm{z}_{0}^{2}}{\mathrm{w}_{0}^{2}} \quad \beta=2 \mathrm{R}_{\mathrm{m}} \mathrm{z}_{0}
$$

From the acoustic potential, the normal velocity in the aperture $(z=0)$ is obtained by $v_{z}=\partial \Phi / \partial z$.

\section{RESULTS}

Two MPS pulses (MPS1 and MPS2) and two superposed Gaussian pulses (SG3 and SG4) were launched from the array. The parameter values for the MPS pulses were $R_{m}=1000$ meters, $z_{0}=0.48 \mathrm{~cm}$., and $w_{0}=7.5 \mathrm{~cm}$. (MPS1) or $w_{0}=21 \mathrm{~cm}$. (MPS2). For the superposed Gaussian pulses we used $f_{0}=30 \mathrm{kHz}, z_{0}=0.0$, and $f_{0}=15 \mathrm{~cm}$ (SG3) or $r=7.5 \mathrm{~cm}$ (SG4). Also, tone bursts of $18,21,35$, and $50 \mathrm{kHz}$ were launched for comparison. The directivity patterns of MPS2, SG3, and SG4 showed narrower central lobes than the tone bursts and lower side lobes. Pulse MPS1 showed a curious double humped central lobe structure. The low side lobes of the LWs occurred at an angle near $\pm 50^{\circ}$, in agreement with the grating lobes of the $50 \mathrm{kHz}$ tone burst. This was further confirmed by the power spectrum of the received pulse at $\pm 50^{\circ}$. In summary, the behavior of the superposed Gaussian pulses compared well with that of the MPS pulses leading us to include them as another member of the class of localized waves.

\section{ACKNOWLEDGMENTS}

This work was performed under the auspices of the United States Dept. of Energy by the Lawrence Livermore National Laboratory under Contract W-7405-Eng-48.

\section{REFERENCES}

1. Lu, J. and \& Greenleaf, J. F., IEEE Trans. Ultrason., Ferroelect. Freq. Contr., 39(1), 19-31 (1992)

2. Brittingham, J. B., J. Appl. Phys. 54(3), 1179-1189 (1983)

3. Ziolkowski, R. W., J. Math. Phys. 26(4), 861-863 (1985)

4. Ziolkowski, R. W., Phys. Rev. A 39(4), 2005-2033 (1989)

5. Stepanishen, P. R., and Sun, J., J. Acoust. Soc. Am., 102(6), 3308-3318 (1997)

6. Lewis, D. K. and Chambers, D. H., "Localized Wave Generation with a Standard Underwater Array", Proceedings of the Joint Meeting of the International Congress on Acoustics and the Acoustical Society of America, Seattle, WA, 1998

7. Shimoda, K., Introduction to Laser Physics, New York: Springer-Verlag, 1986, pp. 59-63. 


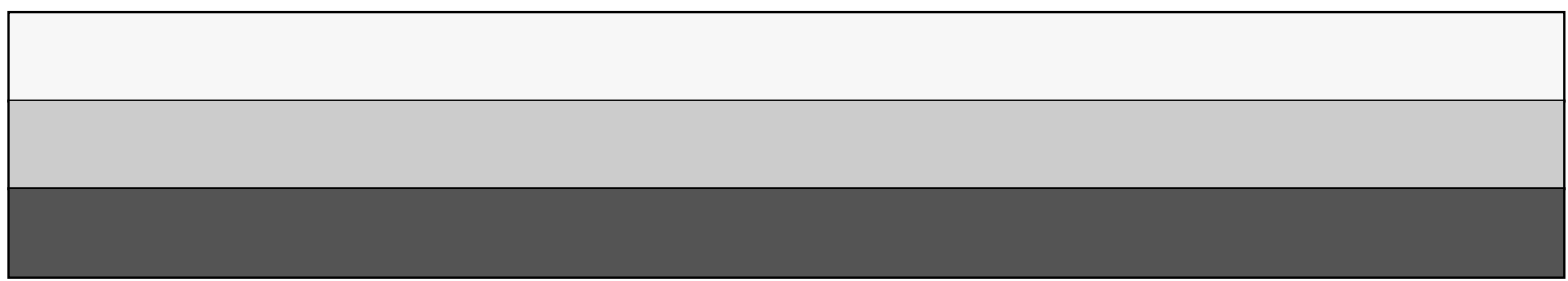

